\title{
Донные осадки озера Тикозеро: предварительные результаты литологического, микропалеонтологического и хронометрического изучения
}

Колька В.В. ${ }^{1}$, Толстобров Д.С. ${ }^{1}$, Корсакова О.П. ${ }^{1}$, Денисов Д.Б. ${ }^{2}$, Косова А.Л. ${ }^{2}$, Толстоброва А.Н. ${ }^{1}$ ${ }^{1}$ Геологический институт КНЦ РАН, Anamumbl, kolka@geoksc.apatity.ru

${ }^{2}$ Институт проблем промышленной экологии Севера КНЦ РАН, Апатить

Аннотация. В статье рассматриваются предварительные результаты изучения донных осадков озера Тикозеро, расположенного в бассейне озера Имандра в Мурманской области России. Донные осадки этого озера являются уникальным природным архивом, позволяющим восстановить историю развития региона в голоцене. В результате работ разрез донных осадков изучен литологическими, микропалеонтологическими методами, проведено радиоуглеродное датирование выделенных слоев. Выполнено сопоставление полученных данных по донным осадкам Тикозера с разрезом торфов, расположенном на его берегу и изученном ранее.

Ключевые слова: литология, диатомовый анализ, радиоуглеродное датирование, голоцен.

\section{Bottom sediments of Lake Tikozero: preliminary results of lithological, micropaleontological, and chronometric studies}

\author{
Kolka V.V. ${ }^{1}$, Tolstobrov D.S. ${ }^{1}$, Korsakova O.P. ${ }^{1}$, Denisov D.B. ${ }^{2}$, Kosova A.L. ${ }^{2}$, Tolstobrova A.N. ${ }^{1}$ \\ ${ }^{1}$ Geological Institute, Kola Sciens Centre, Russian Academy of Sciences, Apatity, kolka@geoksc.apatity.ru \\ 2 Institute of the Industrial Ecology Problems of the North, Kola Science Center, Russian Academy of \\ Sciences, Apatity
}

\begin{abstract}
The article discusses preliminary results of the study of bottom sediments of the Lake Tikozero located in the Lake Imandra basin, Murmansk Region, Russia. The small lake bottom sediments are a unique natural archive that allows us to restore the history of the region development during the Holocene. As a result of the work, the section of the lithological sequence of bottom sediments was studied by lithological, micropaleontological methods; radiocarbon dating of the selected layers was carried out. The obtained data on bottom sediments were correlated with data from a peat section located on the Tikozero coast and previously studied.
\end{abstract}

Key words: lithology, diatom analysis, radiocarbon dating, Holocene.

\section{Введение}

Донные отложения (д.о.), формирующиеся в озерных котловинах, являются замечательными и уникальными природными архивами. Непрерывная их седиментация на протяжении десятков тысяч лет позволяет проследить хронологию трансформации озера и проводить палеогеографические и палеоэкологические реконструкции значительного по площади региона. Актуальность этих исследований в бассейне озера Имандра связана с недостаточной изученностью плейстоценголоценовых палеогеографических обстановок в Кольском регионе, несмотря на то, что изучением развития территории в поздне- и послеледниковое время в пределах Имандровской депрессии занимаются на протяжении многих лет (Лаврова, 1960; Никонов, 1964, и др.).

В течение последнего десятилетия в пределах бассейна оз. Имандра проведены исследования донных отложений нескольких малых озер (Николаева и др., 2015, Толстоброва и др., 2016 и др.). В результате этих работ получены новые литологические и микропалеонтологические данные, проведено радиоуглеродное $\left({ }^{14} \mathrm{C}\right)$ датирование литологических последовательностей донных осадков. Изучение донных осадков оз. Тикозеро продолжают серию комплексных исследований малых озер бассейна оз. Имандра.

Озеро Тикозеро (абсолютная отметка 128.0 м н.у.м.) располагается на восточном берегу оз. Экостровская Имандра (рис. 1), имеет вытянутую форму. Судя по конфигурации и самого оз. Тикозеро, и ближайших к нему заливов Экостровской Имандры, Тик-губы, Тупик-губы, губы Сумтедлухт, его депрессия имеет тектонически предопределенную форму с четко очерченными прямоли- 


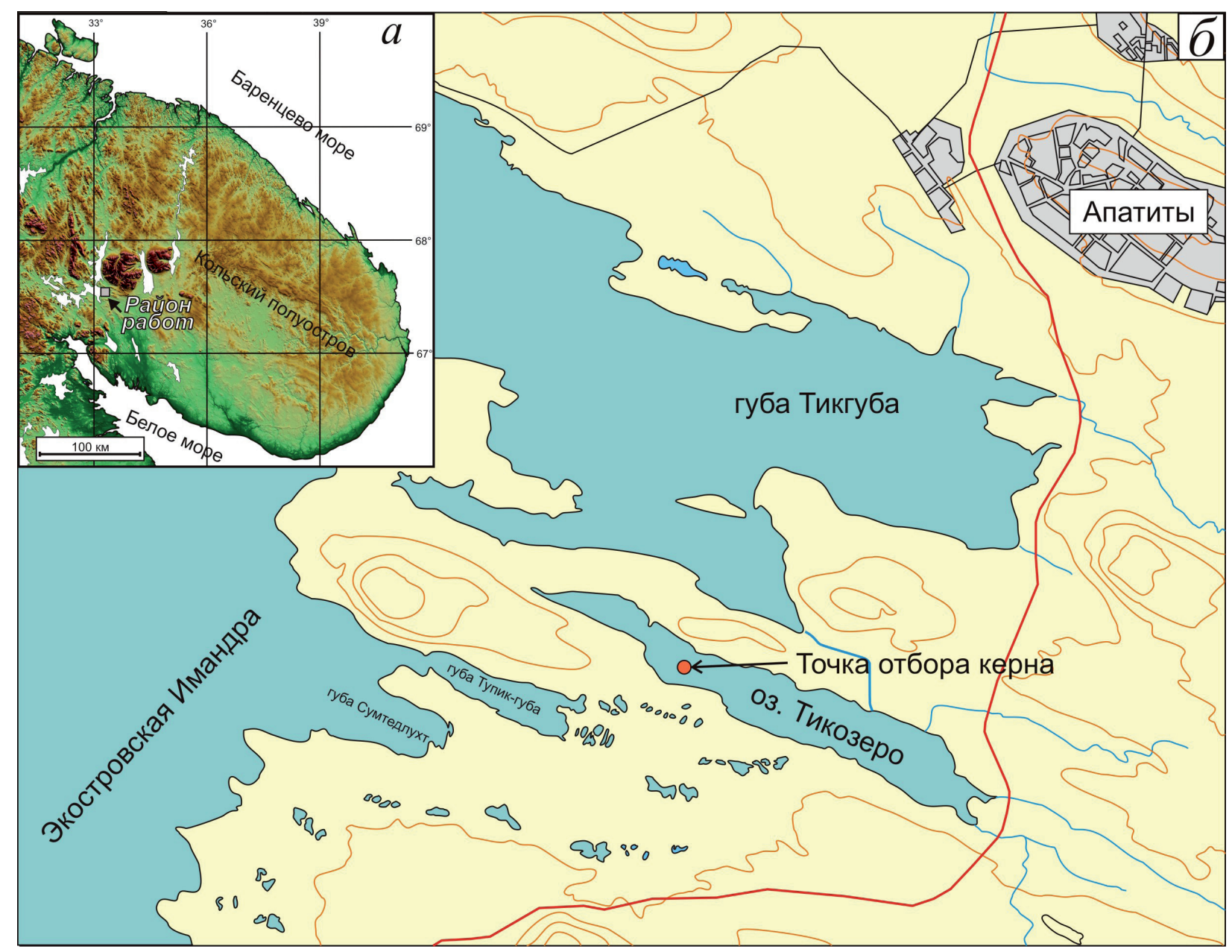

Рис. 1. Район исследования (а) и положение озера Тикозеро в депрессии озера Имандра (б).

Fig. 1. The study area (a) and location of Lake Tikozero in the depression of Lake Imandra (b).

нейными берегами, с простиранием С3-ЮВ. Размеры озера $5500 \times 700$ м, площадь 3.85 км². Отбор керна проводился в западной части озера (6756'20.6" с.ш. $32^{\circ} 47^{\prime} 02.3^{\prime \prime}$ в.д. с глубины 0.55 м.

\section{Литологическая последовательность донных осадков озера Тикозеро}

В разрезе донных отложений вскрыта следующая последовательность осадков (описание снизу вверх, глубина указана от поверхности воды в озере) (рис. 2):

1) 135-110 см - песок серый, тонкозернистый, неслоистый / неотчетливо слоистый. Граница с вышележащим слоем резкая, отчетливая;

2) 110-102 см - гиттия коричневая, слоистая / неотчетливо слоистая, с минеральными частицами. В нижней части слоя отмечаются линзы серовато-белого цвета. В интервале 102-103 см обнаружены включения алеврита (?) темно-серого цвета;

3) 102-97 см - гиттия коричневая, без минеральных частиц. В нижней части на глубине 100-102 см - гиттия монотонная, коричневая с сероватым оттенком, из-за появления минеральных частиц. В интервале 97-100 см - гиттия с неотчетливой косой слоистостью. Границы с выше- и нижележащими слоями неровные;

4) 97-90 см - гиттия коричневая, слоистая, неотчетливо слоистая, по структурно-текстурным признакам похожа на гиттию в интервале $102-110$ см. В данном интервале отмечаются темно-серые включения алеврита (?). Граница с вышележащим слоем неровная, резкая;

5) 90-87 см - гиттия с минеральными частицами, изменение цвета от коричневого до сероватокоричневого. На глубине 87 см - серый прослой алеврита и тонкозернистого песка.

6) 87-55 см - гиттия темно-коричневая, монотонная, рыхлая, без включений. 


\section{Диатомовые комплексы донных отложений оз. Тикозеро}

По всему разрезу отмечается преобладание бентосных форм и обрастателей. Массовые виды - представители рода Brachysira (Brachysira zellensis (Grun.) Round \& Mann, B. brebissonii Ross). Планктонные диатомеи встречались единично, преимущественно виды рода Cyclotella.

Развитие диатомовой флоры началось с самого начала формирования водоема. В низах песков (интервал 130-134 см) обнаружены единичные створки диатомовых водорослей. Выше (интервал 130-110 см) отмечено увеличение видового богатства диатомовых водорослей. Преобладающими являются Sellaphora pupula (Kütz.) Mereschkovsky и Brachysira zellensis.

Выше (интервал 110-102 см), наблюдаются изменения в составе диатомовых комплексов, увеличилось видовое богатство. Преобладают бентосные формы и обрастатели (Brachysira zellensis, виды рода Cymbella). Отмечено присутствие Mastogloia lacustris.

В органогенных осадках (интервал 110-90 см) увеличивается доля Frustulia saxonica Rabenh., а также доля видов рода Cyclotella. Отмечено появление Caloneis obtusa (W.Smith) Cl., а также Brachysira follis (Ehrb.) Rossin Hart. Эти изменения указывают на уменьшение глубины водоема и снижение рН в этот период.

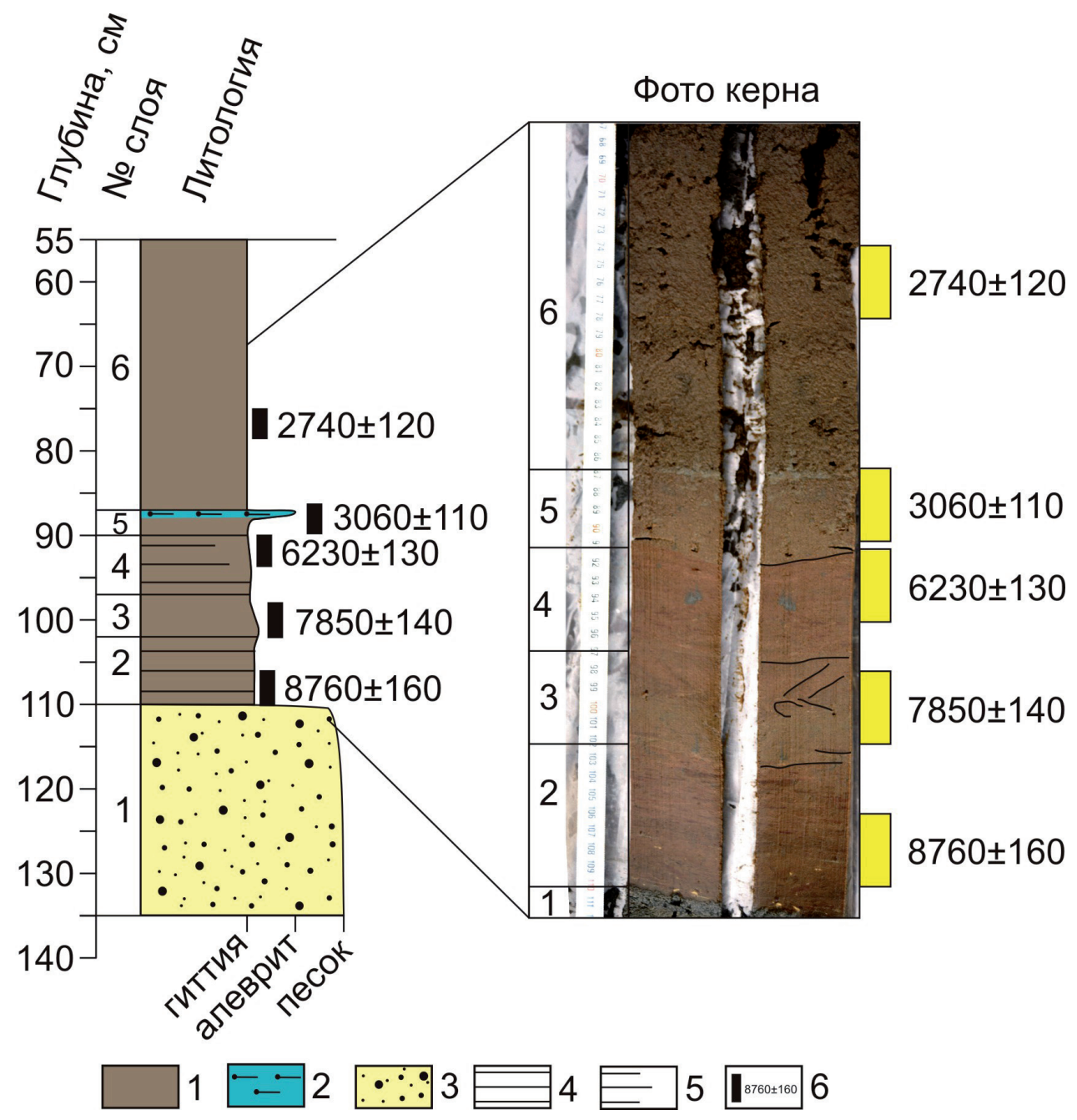

Рис. 2. Литологическая последовательность и фото донных осадков озера Тикозеро.

1 - гиттия; 2 - алеврит; 3 - песок; 4 - слоистость; 5 - неотчетливая слоистость; 6 - интервал отбора пробы на ${ }^{14} \mathrm{C}$ датирование.

Fig. 2. Lithological sequence and photo of Lake Tikozero bottom sediments.

1 - gyttja; 2 - silt; 3 - sand; 4 - lamination; 5 - weak lamination; 6 - sampling interval for ${ }^{14} \mathrm{C}$ dating. 
В интервале 87-86 см отмечается увеличение доли видов рода Pinnularia, бентосного вида Diploneis finnica (Ehrb.) Cl., единично отмечены створки планктонного вида Aulacoseira alpigena. Отмечено высокое содержание минеральных частиц, ломаных створок диатомей. В интервале 75-74 см преобладают ацидофильные виды: Brachysira zellensis, B. brebissonii R. Ross и Frustulia saxonica, отмечено появление видов рода Staurosira, доля которых увеличивается в верх по разрезу В интервале 60-61 см доминирует Brachysira brebissonii, встречаются створки с нарушенной морфологией панциря. Вероятно, увеличение доли представителей семейства Fragilariaceae наряду с появлением аберрантных форм свидетельствует о некоторых последствиях антропогенного загрязнения и эвтрофирования на современном этапе развития водоема.

На протяжении всего периода накопления отложений, в озере развивалась типично пресноводная диатомовая флора, значения $\mathrm{pH}$ были околонейтральными и слабокислыми. Доминировали обрастатели и бентосные виды, планктонные формы встречались единично. Водоем был мелководным, выраженные гидродинамические процессы не выявлены. Очевидно, в озере развивалась высшая водная растительность, служащая субстратом для эпифитных диатомей (представителей Achnanthidiaceae). Отмечен некоторый тренд уменьшения глубины озера на протяжении голоцена. Предварительные результаты показали, что необходим анализ с более высоким разрешением (послойно), для выявления этапов изменения условий седиментации и времени отделения Тикозера от оз. Имандра. Целесообразным представляется реконструкция значений рН для оценки процессов заболачивания приозерной низменности и водосборной территории.

\section{Радиоуглеродное датирование}

Датированы пять образцов из всех выделенных слоев органического материала. Результаты приводятся на рисунке 2. Радиоуглеродное датирование проведено в лаборатории геоморфологических и палеогеографических исследований полярных регионов и Мирового океана Института наук о земле СПбГУ по традиционной методике.

\section{Обсуждение полученных результатов и их сопоставление с данным по разрезу торфяника на берегу оз. Тикозеро}

В 1995 году был подробно изучен разрез торфа, отобранный на берегу оз. Тикозеро с целью отнесения его к стратотипу голоценовых отложений Кольского полуострова (Семенова и др., 2002). По полноте изучености, выраженности палинологических характеристик слоев авторы посчитали его эталонным местным стратотипом голоцена. По месту нахождения разреза свиту, соответствующую по объему голоцену, было предложено называть тикозерской. Разрез (1.55 м) был подробно изучен спорово-пыльцевым анализом и хорошо датирован (10 ${ }^{14} \mathrm{C}$ датировок). Изучение донных осадков малого озера в непосредственной близости от тикозерского стратотипа позволило сравнить наземный (разрез торфа) и озерный (разрез донных осадков озера) природные архивы и дополнить данные по тикозерской свите. Сравнение десяти ${ }^{14} \mathrm{C}$ датировок из торфов и пяти ${ }^{14} \mathrm{C}$ датировок из д.о. показало хорошую их сходимость. Литологическая последовательность разреза д.о. состоит из шести слоев (рис. 2), которые имеют отчетливые границы, различные текстуры и по хронологии соответствуют пяти палинозонам выделенным в разрезе торфа (Семенова и др., 2002).

Слой 1 (интервал 135-110 см, рис. 2) соотносится с интервалом 165-157 см в торфяном разрезе и палинозоной 1. Характер споровопыльцевых спектров здесь соответствует пребореальному периоду голоцена (Семенова и др., 2002). Диатомовая флора, найденая в осадках слоя 1, характерна для суровых климатических условий арктических водоемов, с промерзанием водоема до дна, коротким вегетационным периодом при низких температурах, а также обедненностью воды питательными веществами (снеговым питанием). В начале пребореала происходила быстрая фронтальная дегляциация Фенноскандинавского ледника в районе оз. Имандра и отступание края ледника на запад. Полученные данные показывают, что во второй половине пребореала в Имандровской депрессии уже существовал обширный континентальный бассейн пра-Имандры. Конфигурация его береговой линии менялась в сторону сокращения площади и образования на побережье изолированных малых озер. Именно в это время (вторая половина, конец пребореала) мелководный залив Экостровской Иман- 
дры, в котором проходила седиментация песков слоя 1 (рис. 2), отделился и превратился в мелководное оз. Тикозеро. Резкий перерыв в осадонакоплении минерагенной части разреза (слой 1) и органогенной части (слои 2-6) свидетельствуют об этом.

Cлои 2, 3 (интервал 110-97 см., рис. 2) литологически представлены гиттией слоитой и неслоистой, с наличием минеральной фракции, которая может в некоторых частях интервала отсутствовать. Между слоями обнаруживается литологическое несогласие, которое, вместе с наклонной слоистостью, может свидетельствовать о изменении гидродинамических условий в водоеме в это время. Здесь наблюдается изменение в составе диатомовых комплексов, увеличивается их видовое богатство. Преобладают бентосные формы и обрастатели (Brachysira zellensis, виды рода Cymbella), что характеризует мелководность бассейна. Отмечено присутствие Mastogloia lacustris.

Для этих интервалов получены две ${ }^{14} \mathrm{C}$ датировки (рис. 2), которые свидетельствуют о том, что слои формировались в бореальное время голоцена. Слои 2 и 3 д.о. оз. Тикозеро по времени формирования соотносятся с интервалом торфа (157-138 см) в торфяном разрезе, где выделена палинозона 2 (Семенова и др., 2002) для которой характерно резкое сокращение присутствия кустарничковой березы и доминирование пыльцы сосны и древовидной березы.

Слой 4 (интервал 97-90 см, рис. 2), которым завершается седиментация плотной гиттии, формировавшейся на минеральном субстрате с бореала. Выше с отчетливым литологическим несогласием начинает накапливаться более рыхлая и более светлая гиттия серо-коричневого цвета. В данном интервале отмечаются темно-серые включения окатышей алеврита (?). Присутствие диатомового вида Caloneis obtusa (W.Smith) Cl., бентосного ацидофила, специфичного для засушливых периодов, а также Brachysira follis (Ehrb.) Rossin Hart. может свидетельствовать о временном пересыхании или значительном обмелении с последующим обводнением озера и проявлением бурных гидродинамических условий в нем. Этой гидродинамической активизацией можно объяснить образование окатышей алеврита в гиттии, и выраженное литологическое несогласие на границе с вышележащим слоем. Кроме резкого и неровного контакта между слоями 4 и 5 об этом свидетельствуют датировки из этих слоев. Образцы для датирования, отобранные над этой границей и под ней на незначительном расстоянии, показывают разницу во времени формирования этих интервалов более 2500 лет.

Интервал слоя 4 в последовательности д.о. по хронологическим данным можно сопоставить с интервалом 138-48 см в торфяном разрезе (Семенова и др., 2002) и относится к 3 палинозоне, которая соответствует атлантическому периоду голоцена. Для палиноспектров этой палинозоны основной доминантой являются пыльца сосны (до 70 \%), березы древовидной (10-25 \%), характерно постоянное присутствие пыльцы широколиственных (вяза, липы, дуба). Интервалы д.о. и торфа хорошо сопоставляются по данным хронометрии.

Слой 5 (интервал 90-87 см, рис. 2) представлен боле светлой серовато-коричневой гиттией с минеральными частицами, количество которых увеличивается вверх по разрезу и на верхней границе формирует тонкий прослой алеврита, тонкозернистого песка. В вехней части интервала и сразу над ним (87-86 см) отмечается увеличение доли видов рода Pinnularia, бентосного вида Diploneis finnica (Ehrb.) Cl., единично отмечены створки планктонного вида Aulacoseira alpigena. В образце отмечено высокое содержание минеральных частиц, ломаных створок диатомей. Это может свидетельствовать о значительной гидродинимической активности в озере в это время.

Датировка, полученная из этого интервала свидетельсвует, что он формировался в суббореальное время голоцена. Согласно данным споровопыльцевого анализа в это время отмечается тренд на похолодание, т.к. в палиноспектрах уже отсуствует пыльца широколиственныхи уменьшается количество древовидной березы.

Слой 6 (интервал 87-55 см, рис. 2) представлен гиттией темно-коричневой, монотонной, рыхлой, без включений. Согласно с радиоуглеродной датировкой и данными споропыльцевого анализа по разрезу торфа (Семенова и др., 2002) этот интервал формировался в суббореальное время. Данные диатомового анализа свидетельствуют о влиянии процессов эвтрофикации в озере и возможного антропогенного влияния на заключительных этапах формирования донных осадков. 
Полевые работы и аналитические работы выполняются в рамках гранта РФФИ 18-05-60125 Арктика «Крупные озера Арктики в условиях глобальных и региональных изменений окружающей среды и климата», сопоставление с разрезом торфяников проведено для выполнения темы НИР 0226-2019-0054 лаборатории №43 Геологического института КНЦ РАН.

\section{Литература}

1. Лаврова М.А. Четвертичная геология Кольского полуострова. М.- Л. Изд-во: АН СССР. 1960. 234 c.

2. Николаева С.Б., Лаврова Н.Б., Толстобров Д.С., Денисов Д.Б. Реконструкция палеогеографических обстановок голоцена в районе озера Имандра (Кольский регион): результаты палеолимнологических исследований // Труды Карельского научного центра РАН. 2015. № 3. С. 34- 47.

3. Никонов А. А. Развитие рельефа и палеогеография антропогена на западе Кольского полуострова. М-Л. Изд-во: Наука. 1964. 181 с.

4. Семенова Л.Р., Савельева Л.А., Арсланов Х.А., Джиноридзе Е.Н., Чернов С.Б. Максимов Ф.Е., Тертычная Т.В., Колька В.В., Корсакова О.П. Стратотип голоценовых отложений на Кольском полуострове (г. Апатиты) // Сборник материалов Третьего Всероссийского совещания по изучению четвертичного периода, Смоленск. Т. 2. Смоленск. Изд-во: СГПУ. С. 62-63.

5. Толстоброва А.Н., Толстобров Д.С., Колька В.В., Корсакова О.П. История развития озера Осиновое (Кольский регион) в поздне-постледниковое время по материалам диатомового анализа донных отложений // Труды Карельского научного центра РАН. 2016. Серия Лимнология. № 5. С. 106-116. 